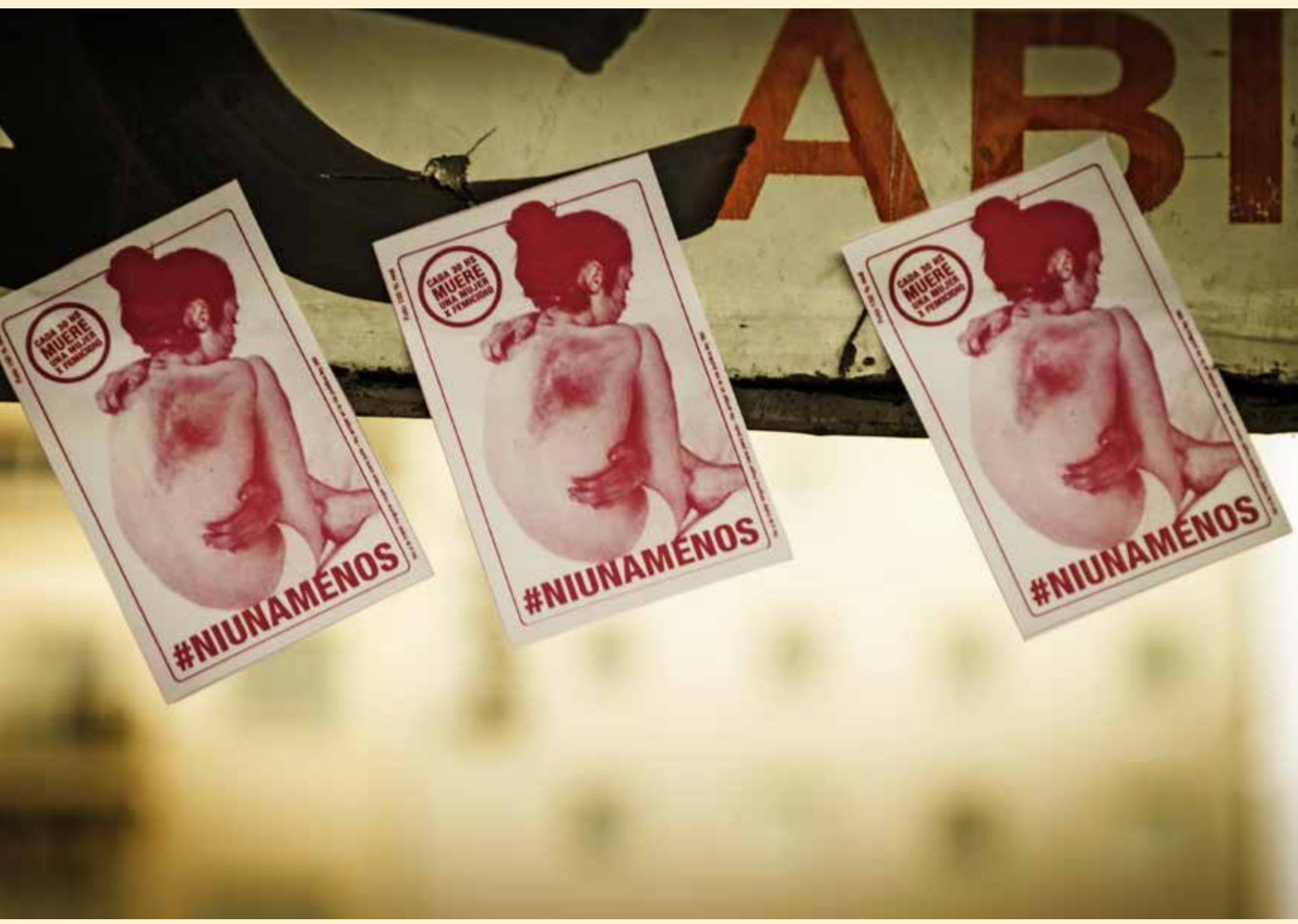

Las fotografías de este artículo corresponden al archivo de la Investigación fotográfica: Ojo Dentado. Salvador BataIla. (Coord.). Sergio Ranzoni y Andrea Podestá. 


\section{Pasajes del NiUnaMenos. De la Soledad a la Masa}

Ensayo fotográfico sobre un proceso de performance-investigación

Investigación fotográfica: Ojo Dentado: Salvador Batalla (coord.), Sergio Ranzoni y Andrea Podestá.

Investigación performática: Equipo de Antropología del Cuerpo y la Performance: Silvia Citro (coord.), Cinthya Pinsky, Adil Podhajcer, Carina do Brito y Tamia Rivero.

Fac. de Filosofía y Letras, Universidad de Buenos Aires. www.antropologiadelcuerpo.com

DOI: https://doi.org/10.14483/25909398.15509

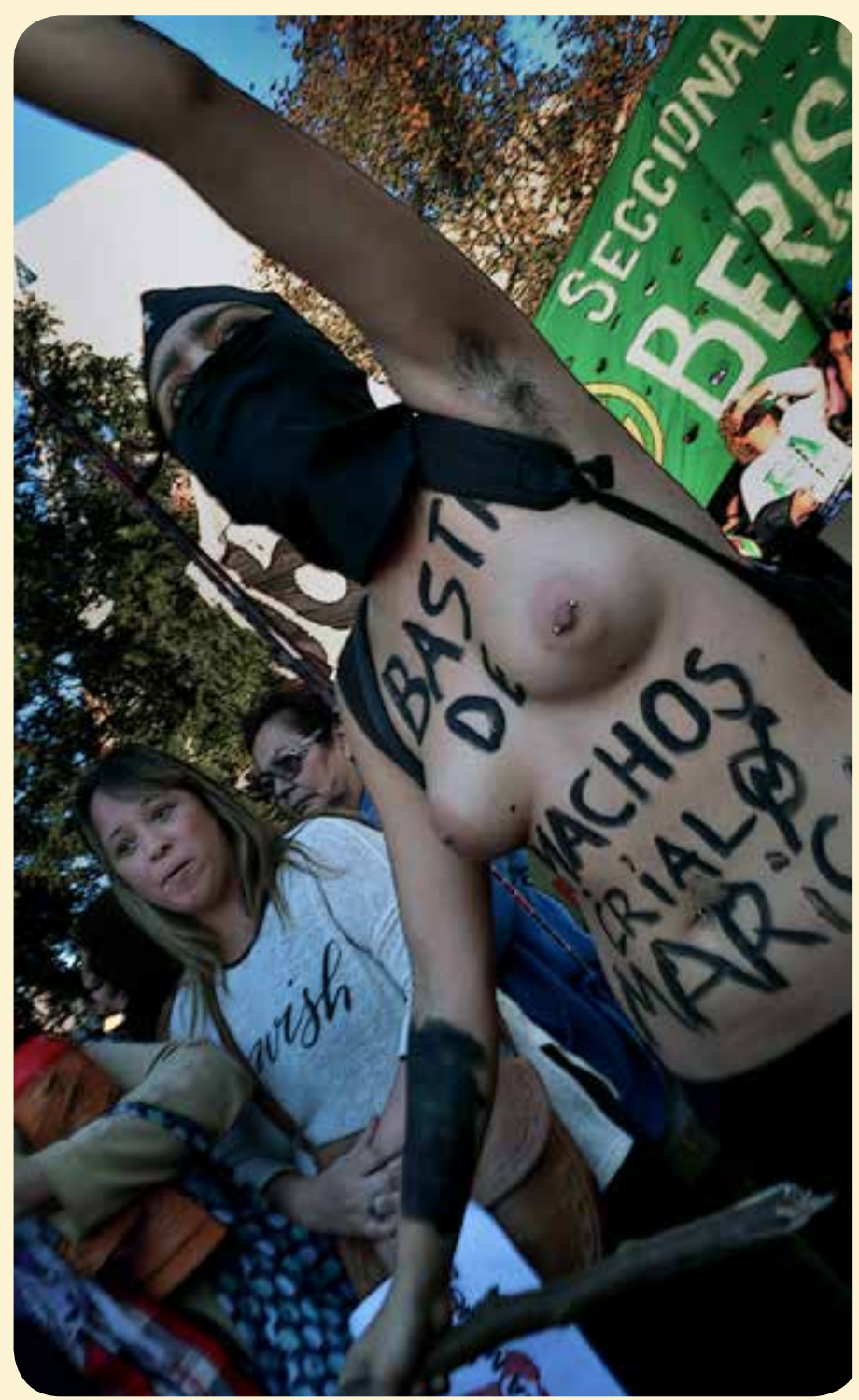


Este ensayo fotográfico resume el proceso colectivo de investigación-creación desarrollado entre 2016-2017 por integrantes del Equipo de Antropología del Cuerpo y la Performance de la Universidad de Buenos Aires, en colaboración con el Colectivo de Imágenes Ojo Dentado, a partir de las "Marchas del Ni Una Menos" en la ciudad de Buenos Aires. La marcha del 3 de junio de 2015 fue la primera marcha auto-convocada contra la violencia de género que adquirió un carácter tan masivo, abriendo una nueva etapa de la historia de la lucha por los derechos de las mujeres en Argentina.

A partir del registro fotográfico, audiovisual y etnográfico de las performances, visualidades e instalaciones creativas desplegadas en las marchas por Ixs manifestantes, iniciamos un proceso de investigación-creación sobre estas experiencias de violencia en nuestras propias genealogías. De ahí emergieron instalaciones multimediales interactivas, que invitaban a los espectadores participantes a explorar colectivamente estas problemáticas. Este proceso es parte de las metodologías trans- disciplinarias de performance-investigación elaboradas por nuestro equipo, las cuales intentan recuperar el potencial poético-epistemológico-político de las corporalidades y materialidades sensibles y en movimiento. Así, planteamos que estas metodologías encarnadas propician no solo la reflexión crítica sobre los regímenes de desigualdad social y violencia, sino también la emergencia de provisorias líneas de fuga, que en su articulación colectiva, podrían potenciar prácticas de re-existencia y transformación micropolítica.

Una versión más amplia de este proceso, puede verse en el siguiente video:

https://vimeo.com/255673236

Y en el artículo:

https://www.academia.edu/40251933/_Pasajes_del_Ni_ Una_Menos_._Reflexiones_metodol\%C3\%B3gicas_sobre_un_ensayo_colectivo_de_performance-investigaci\%C $3 \%$ B 3 n 


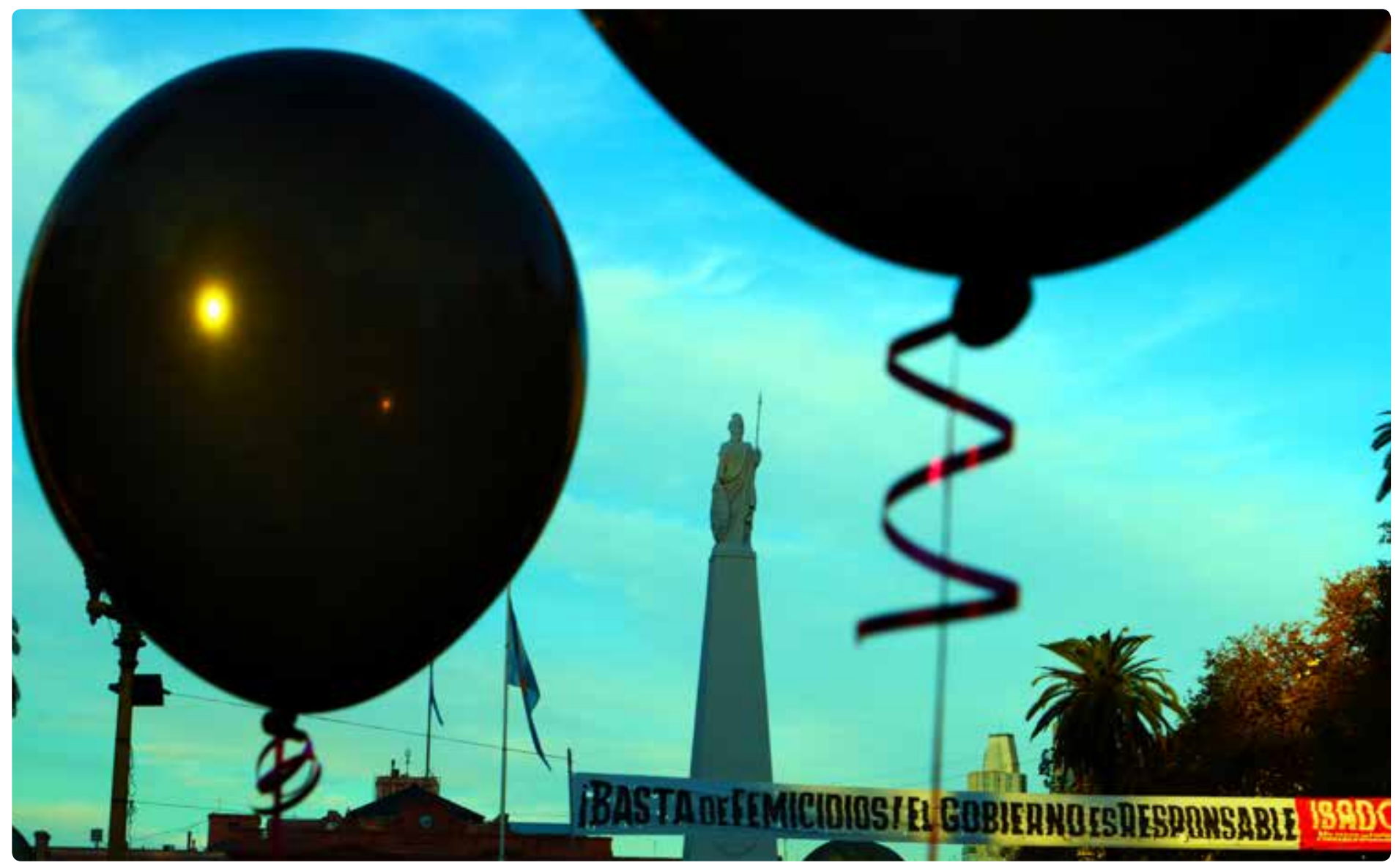

Las fotografías de este artículo corresponden al archivo de la Investigación fotográfica: Ojo Dentado. Salvador BataIla. (Coord.). Sergio Ranzoni y Andrea Podestá. 


\section{(6). 1 옹}

f ज्ञ Uiा

2. WENOS

\section{a}

8

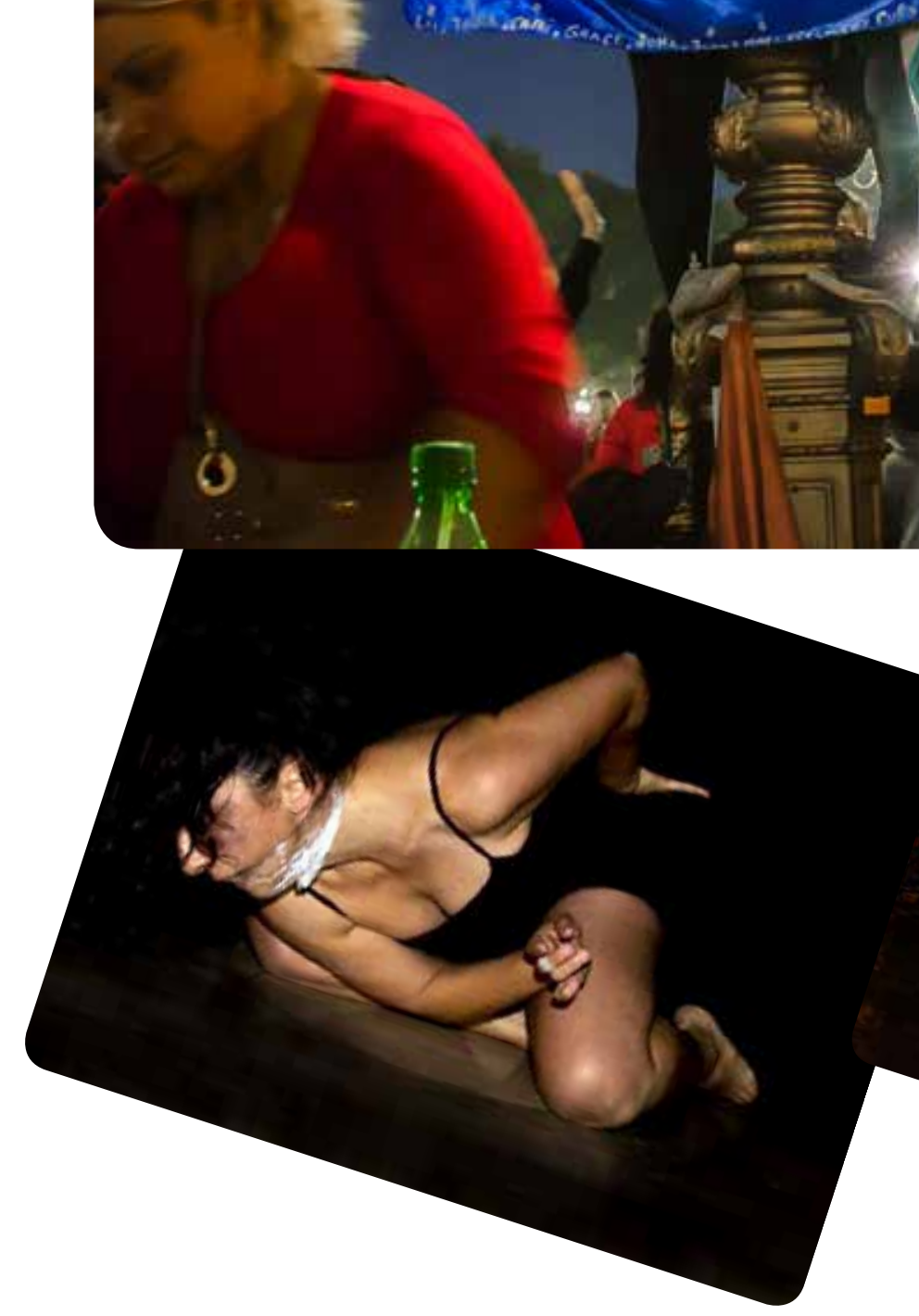

$-1$
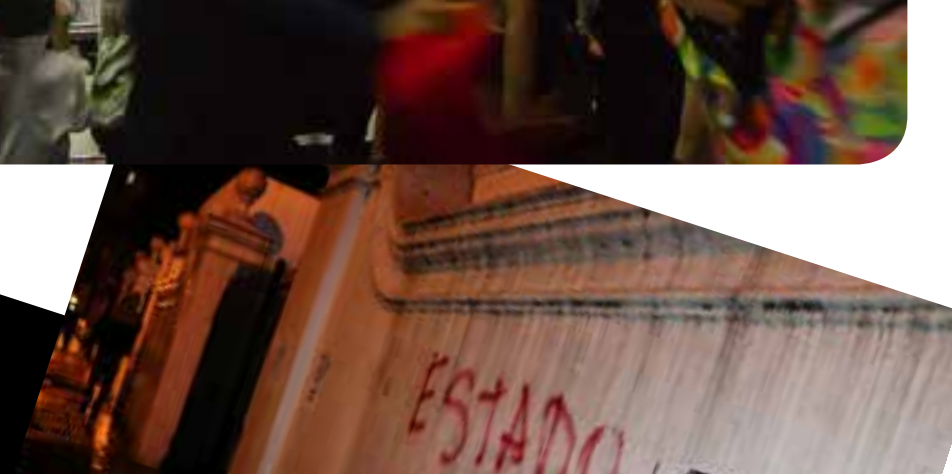


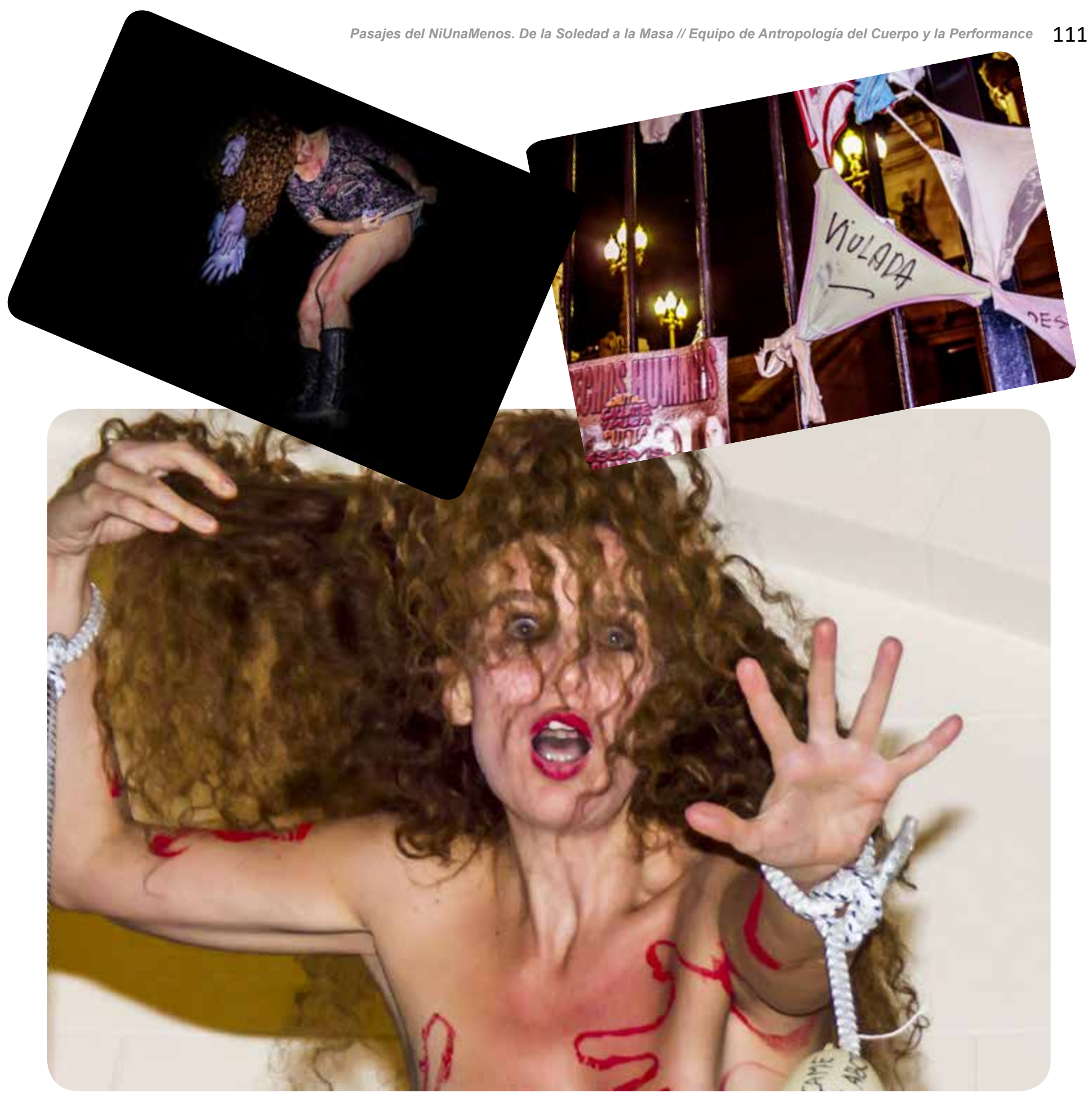

Las fotografías de este artículo corresponden al archivo de la Investigación fotográfica: Ojo Dentado. Salvador Batalla. (Coord.). Sergio Ranzoni y Andrea Podestá. 


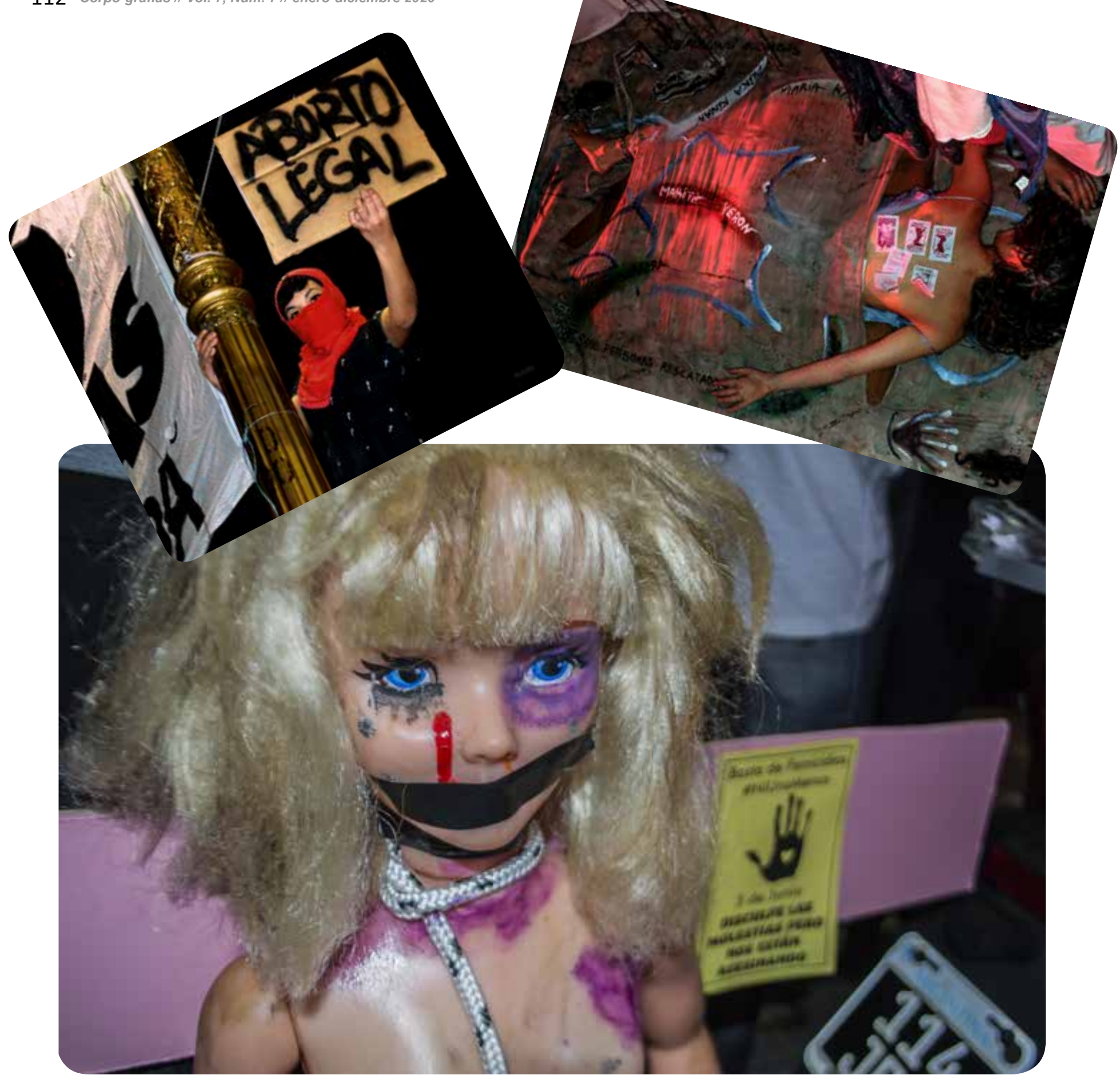

Las fotografías de este artículo corresponden al archivo de la Investigación fotográfica: Ojo Dentado. Salvador Batalla. (Coord.). Sergio Ranzoni y Andrea Podestá. 


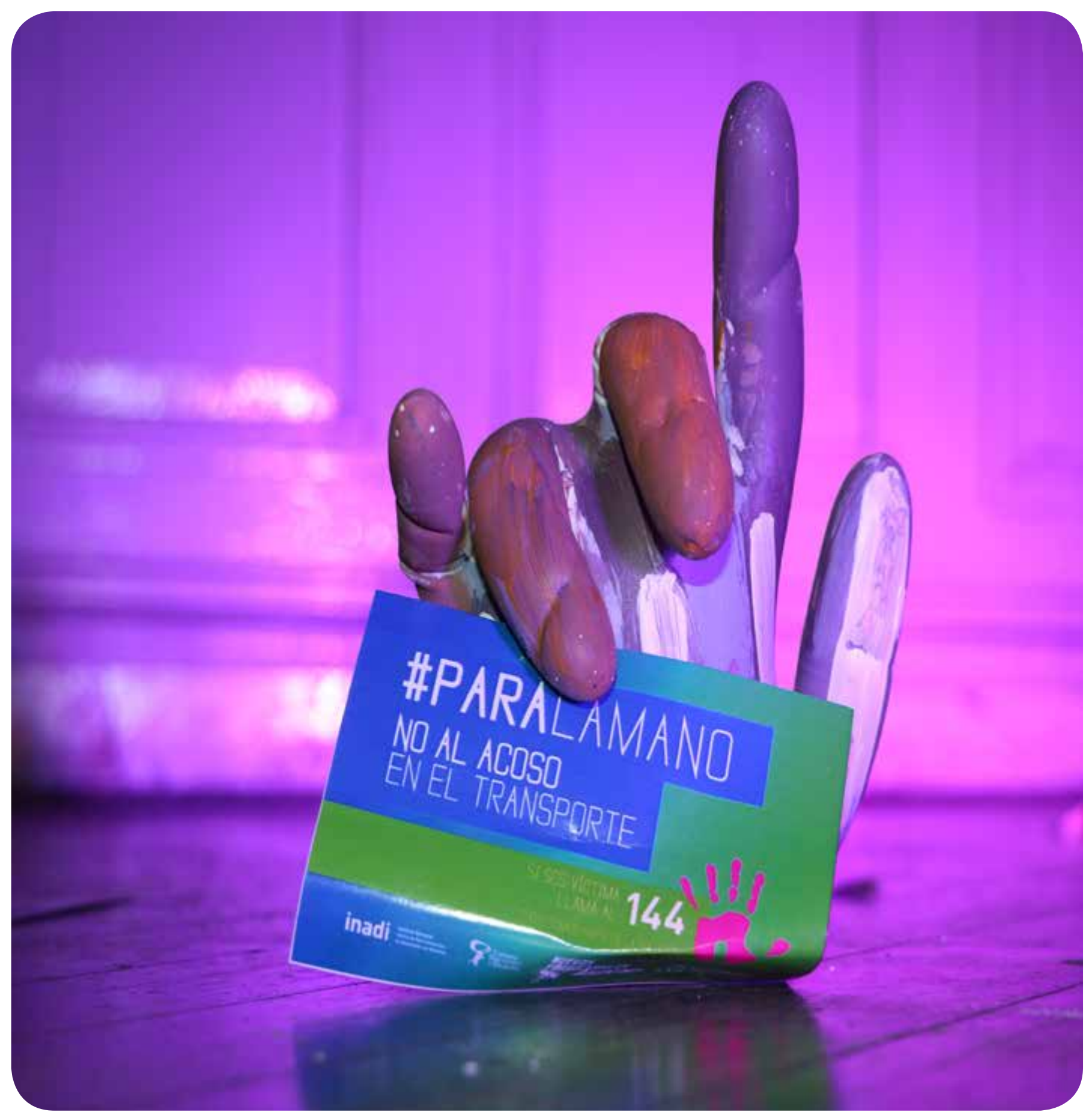


El Equipo de Antropología del Cuerpo y la Performance (www.antropologiadelcuerpo.com) de la UBA se crea en el año 2004, conformado por docentes e investigadores provenientes de la Antropología y las Artes. Con la coordinación general de la Dra. Silvia Citro, desarrollamos diversos proyectos de investigación y publicaciones, así como performances y producciones visuales y audiovisuales, que buscan articular el saber-hacer artístico con el de las disciplinas humanísticas y sociales. En 2004 organizamos el primer simposio sobre Antropología del Cuerpo en el marco de los Congresos Argentinos de An-

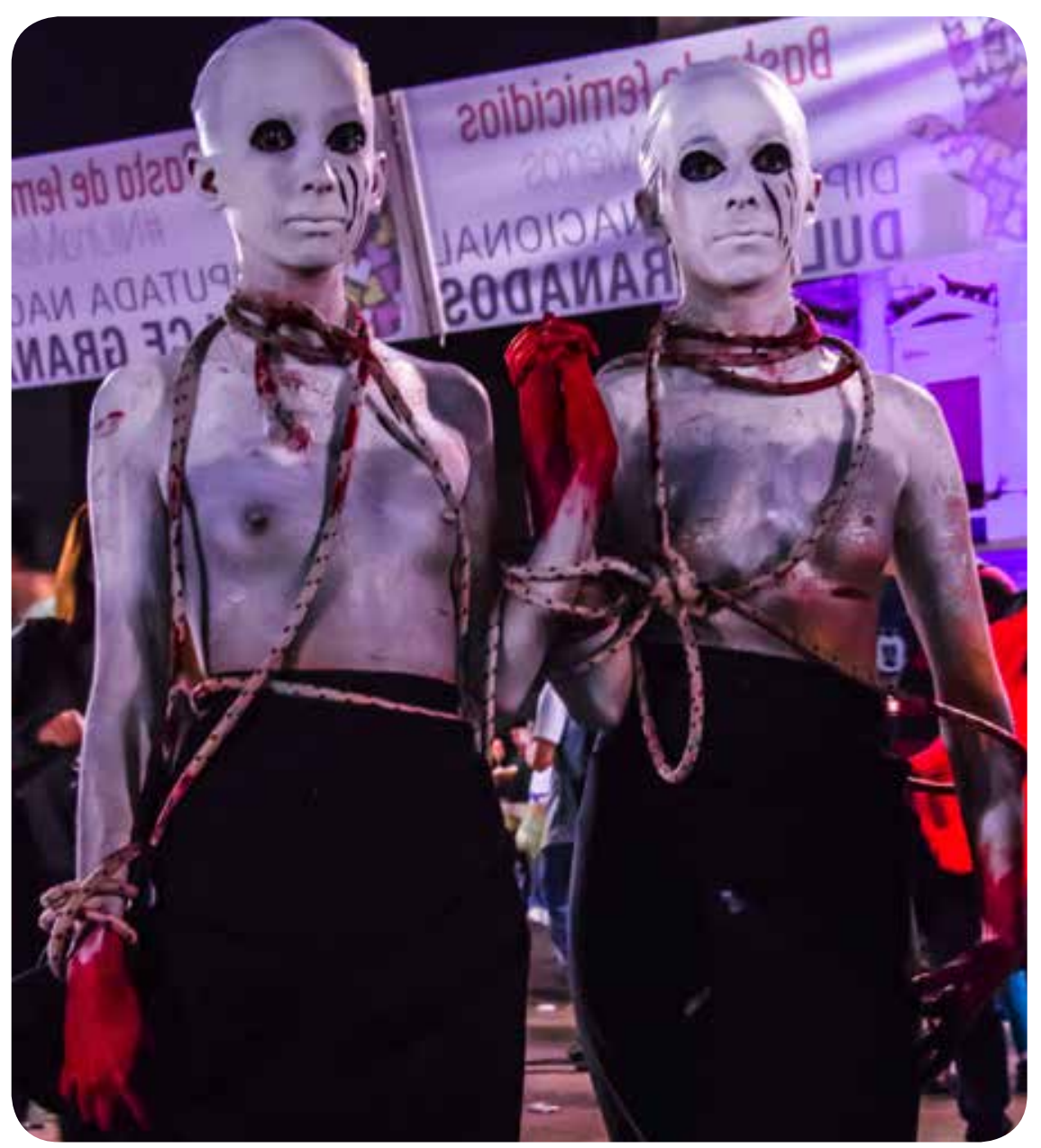

Las fotografías de este artículo corresponden al archivo de la Investigación fotográfica: Ojo Dentado. Salvador Batalla. (Coord.). Sergio Ranzoni y Andrea Podestá. 
tropología Social, en 2005 en la Asociación Latinoamericana de Antropología y en 2007 en las Reuniones de Antropología del Mercosur, continuando hasta el presente con estos y otros espacios de discusión. En 2012, junto con otros colegas, impulsamos la conformación de la Red de Antropología de y desde los cuerpos (http://red.antropologiadelcuer- po.com), la cual lleva organizados ya tres Encuentros Latinoamericanos de Investigadores sobre Cuerpos y Corporalidades en las Culturas, en Argentina, Colombia y México; y desde 2014, organizamos las Jornadas de Performance-Investigación, con el auspicio de la UBA y el CONICET.

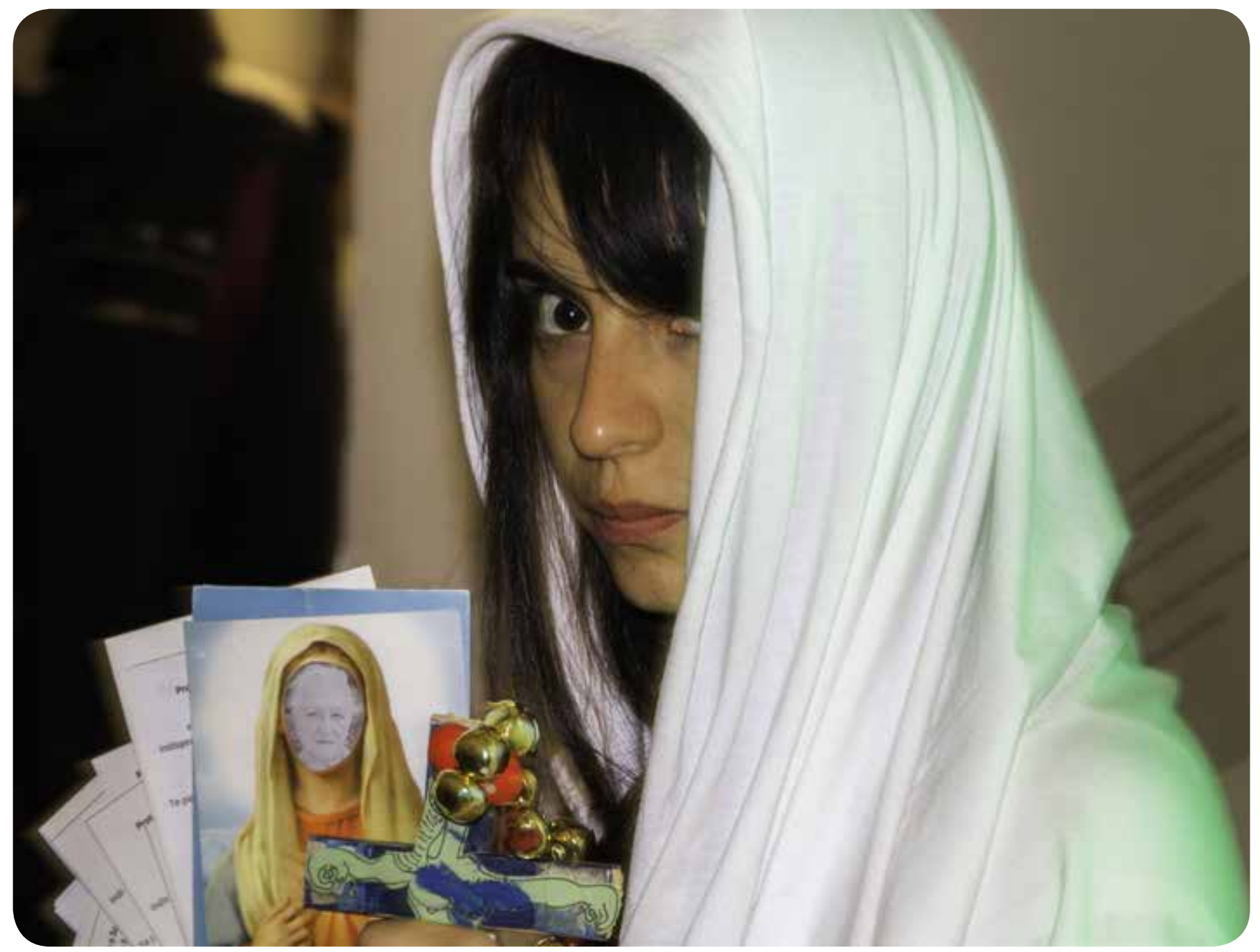

